\title{
ПРОДУКЦИЯ РОЗМАРИНОВОЙ КИСЛОТЫ В ПРОРОСТКАХ МЕЛИССЫ (Melissa officinalis L.) ПОД ВЛИЯНИЕМ ИОНОВ МЕДИ*
}

\author{
K. ESMAEILZADEH-SALESTANI 1,5 $₫$, A. RIAHI-MADVAR ${ }^{2,3}$, M.A. MAZIYAR $^{4}$,
} B. KHALEGHDOUST 5 , E. LOIT 5

Розмариновая кислота (RA), одно из важнейших биологически активных соединений, которое синтезируют растения мелиссы (Melissa officinalis L.), обладает противовирусными, антибактериальными, антиоксидантными и противораковыми свойствами. Кроме того, ее применяют как приправу и для улучшения качества выпечки. Ионы меди действуют как кофактор нескольких белков и играют ключевую роль в фотосинтезе, дыхании, синтезе лигнина, реакциях на окислительный стресс и в метаболизме компонентов клеточной стенки, но в высоких концентрациях могут быть токсичны для растений. Мы предположили, что абиотические стрессы как один из внешних факторов, индуцирующих защитный механизм растений, могут способствовать выработке вторичных метаболитов и особенно RA у представителей семейства Lamiaceae. B представленной работе мы изучали накопление RA, экспрессию гена тирозинаминотрансферазы (TAT), содержание флавоноидов и антоцианов, а также активность антиоксидантных ферментов системы защиты растений от окислительного стресса у 45-суточных проростков $M$. officinalis после обработки разными концентрациями $\mathrm{Cu}^{2+}(0,5,10,20$ и 30 мкM). Образцы собирали и исследовали после 8 и 16 ч обработки $\mathrm{Cu}^{2+}$. Показано, что в меньших концентрациях ионы $\mathrm{Cu}^{2+}$ положительно влияли на накопление RA независимо от длительности обработки, с чем согласовывалось увеличение экспрессии гена TAT, вовлеченного в один из путей синтеза RA. Содержание флавоноидов, антоцианов и растворимого белка в проростках значительно снижалось (за исключением проростков, обработанных в течение 8 ч $\mathrm{Cu}^{2+}$ в концентрации 20 и 30 мкM). Содержание RA и экспрессия гена TAT значительно снизились при максимальной концентрации $\mathrm{Cu}^{2+}$ и длительном воздействии (16 ч). Одновременно в этих проростках мы отмечали повышение активности супероксиддисмутазы и пероксидазы. Последнее может указывать на то, что более низкие концентрации Сu ${ }^{2+}$ вызывают окислительный стресс, активные формы кислорода (АФК), которые выполняют роль сигнальных молекул, накапливаются, и из-за их положительного воздействия на экспрессию гена ТАТ образуется больше RA. Напротив, при самой высокой концентрации ионов меди АФК подавляли экспрессию гена ТАТ и тем самым предотвращали деградацию продукта гена.

Ключевые слова: антиоксидантный фермент, Melissa officinalis, розмариновая кислота, тирозинаминотрансфераза, флавоноиды, антоцианы, супероксиддисмутаза, каталаза, пероксидаза.

Розмариновая кислота (RA) представляет собой сложный эфир кофейной кислоты и 3,4-дигидроксифениллмолочной кислоты. У растений мелиссы (Melissa officinalis L.) RA идентифицирована как одно из основных биологически активных фенольных соединений $(1,2)$. Она обладает противовоспалительным (3), противовирусным (4), антибактериальным, антиоксидантным $(5,6)$, противоопухолевым (7) и противоаллергическим (8) действием. Кроме того, RA может способствовать улучшению качества хлебобулочных изделий (9). RA синтезируется в растении двумя разными метаболическими путями. Путь фенилпропаноидов, который считается основным путем биосинтеза, начинается с активации фермента фенилаланинаммиак-лиазы (ЕC 4.3.1.24) (PAL) и использует аминокислоту фенилаланин в качестве субстрата. Второй путь инициируется реакцией тирозинаминотрансферазы (ТАТ), в которой в качестве субстрата используется тирозин (1).

Ранее сообщалось, что на продукцию RA в растении может влиять присутствие углеводов (10), дрожжевого экстракта, ионов $\mathrm{Ag}^{+}$и метилжасмонатов (11-13). Эксперименты показали, что обработка как $\mathrm{Ag}^{+}$, так и дрожжами увеличивает активность ТАТ и снижает активность PAL в волосатых корнях Salvia miltiorrhiza (13). Было продемонстрировано, что воздей-

\footnotetext{
* Авторы выражают признательность за финансовую поддержку, предоставленную Institute of Science and High Technology and Environmental Sciences, Graduate University of Advanced Technology, Kerman, Iran. 578
} 
ствие $\mathrm{Cu}^{2+}$ на Phyllanthus tenellus увеличивает активность PAL в листьях (14). Аналогичное повышение активности PAL наблюдалось в листьях Camellia sinensis в присутствии меди, ртути и никеля (15).

Медь - незаменимый микроэлемент для роста и развития растений, она действует как кофактор нескольких белков, таких как пластоцианин (PC), $\mathrm{Cu} / \mathrm{Zn}$ супероксиддисмутаза (Cu/Zn SOD) (16), цитохром С оксидаза (17) и играет ключевую роль в фотосинтезе, дыхании, синтезе лигнина, реакциях на окислительный стресс и в метаболизме компонентов клеточной стенки (18). Этот элемент, наряду с другими микроэлементами, отвечает за устойчивость растений к болезням (19). Медь широко присутствует в природе и необходима для роста растений, однако ее высокие концентрации могут быть токсичными для растений (20).

Растения, подверженные воздействиям тяжелых металлов, часто сталкиваются с окислительным стрессом и, как следствие, с высоким уровнем образования активных форм кислорода (АФК) (15). Растения предотвращают повреждения, вызванные АФК, с помощью антиоксидантных систем, функционирующих с участием как веществ неферментативной природы (аскорбиновая кислота, глутатион, токоферол, флавоноиды и др.), так и ферментов (каталаза, пероксидаза, супероксиддисмутаза, глутатион, аскорбатпероксидаза и редуктаза) (21).

Фенольные соединения играют важную роль в механизме стабилизации цвета (22) и защите растений от атак патогенов (23) и ультрафиолетовых лучей (24). Кроме того, они используются в качестве индикаторов для исследования стрессов и улавливателей свободных радикалов $(25,26)$.

Мы предположили, что абиотические стрессы как один из внешних факторов, индуцирующих защитный механизм растений, могут способствовать выработке вторичных метаболитов и особенно розмариновой кислоты у представителей семейства Lamiaceae.

Цель исследования - обработать проростки мелиссы разной концентрацией ионов $\mathrm{Cu}^{2+}$ и измерить количество продуцируемой розмариновой кислоты, а также проанализировать состояние связанных с реакцией на стресс механизмов защиты растений (содержание флавоноидов и антоцианов, а также активность антиоксидантных ферментов). Дополнительно мы измеряли экспрессию одного из ключевых генов биосинтеза RA в проростках M. officinalis - гена тирозинаминотрансферазы TAT.

Meтодика. Семена мелиссы F1 (M. officinalis) были получены из Pakanbazr (Esfahan, Iran). Использовали метанол (чистота для ВЭЖХ) и ортофосфорную кислоту производства компании «Merck» (Германия). Вода (чистота для ВЭЖХ) подавалась с помощью системы мембранной очистки. Внешний стандарт $\mathrm{RA}\left(\mathrm{C}_{18} \mathrm{H}_{16} \mathrm{O}_{8}, \mathrm{MW}=360 \Gamma^{\cdot}\right.$ моль $\left.^{-1}\right)$ и другие аналитические реагенты были приобретены в компании «Sigma» (США).

Семена обрабатывали $2 \%$ раствором гипохлорита натрия, трижды промывали стерильной дистиллированной водой, затем высаживали в среду MS (Murashige and Skoog, 1962) с 0,8 \% агара (w/v) и помещали на инкубацию в регулируемые условия (темнота, относительная влажность $55 \pm 5 \%$, $\left.28 \pm 2{ }^{\circ} \mathrm{C}\right)$ на 2 нед. Затем растения переносили в условия 16/8 ч (свет/темнота) при $30 \pm 2{ }^{\circ} \mathrm{C}$. В возрасте 45 сут проростки извлекали из агаризованной среды, тщательно промывали стерильной дистиллированной водой и переносили в жидкую среду MS. В среду добавляли $\mathrm{Cu}^{2+}$ до конечных концентраций 0 (контроль), 5, 10, 20 и 30 мкМ (использовали соль $\mathrm{CuSO}^{4} \cdot 5 \mathrm{H}_{2} \mathrm{O}$. Как и в предыдущей нашей работе, обработка продолжалась в течение 8 и 16 ч (27). Обработанные проростки собирали, несколько раз промывали стерильной дистиллированной водой для удаления поверхностных ионов и 
разделяли на две части: одну сушили в тени (в течение 3 сут) и использовали для измерения концентрации RA, другую ополаскивали, обезвоживали, замораживали в жидком азоте и хранили при $-80{ }^{\circ} \mathrm{C}$ для последующего измерения содержания флавоноидов и антоцианов, активности антиоксидантных ферментов и анализа уровня экспрессии гена ТАТ.

Идентификацию и количественную оценку RA выполняли, как описано ранее $(27,28)$. Навеску высушенного образца $(0,1$ г) измельчали до состояния порошка и смешивали с 25 мл раствора этанол:вода (30:70 v/v), затем в течение 10 мин обрабатывали ультразвуком и центрифугировали при 4500 об мин $^{-1}$ в течение 5 мин при $4{ }^{\circ} \mathrm{C}$. Супернатант переносили в чистую пробирку, объем доводили до 50 мл стерильной дистиллированной водой. Экстракт фильтровали с помощью одноразового шприцевого фильтра (размер пор 0,2 мкм) перед введением в колонку для высокоэффективной жидкостной хроматографии (ВЭЖХ, колонка ZORBAX SB-C18, Agilent 1100 series, «Agilent», США). Подвижная фаза - 40 \% растворителя А (ортофосфорная кислота в воде, $1,0 \% \mathrm{v} / \mathrm{v}$ ) и $60 \%$ растворителя В (ортофосфорная кислота в метаноле, $1,0 \%$ v/v), скорость потока элюента 1,0 мл • мин ${ }^{-1}$, температура комнатная. RA идентифицировали на основе сравнения времени удерживания образца и стандарта при $\lambda=330$ нм.

Набор RNX plus ${ }^{\mathrm{TM}}$ («Cinnagen», Иран) применяли для экстракции тотальной РНК, как указано в протоколе производителя. Качество и количество экстрагированной РНК оценивали соответственно с помощью разделения в 1 \% агарозном геле и спектрофотометрии (Varian cary 50, «Agilent», Австралия). Для синтеза кДНК использовали M-MuLV Reverse Transcriptase (200 U • мКл $^{-1}$, «Fermentas», EP0441, США), Oligo(dT)20 Primer («Fermentas», SO131, США), dNTP (по 1 мМ каждого) и 20 U RiboLock RNase Inhibitor («Thermo Fisher Scientific», США), реакцию проводили при $42{ }^{\circ} \mathrm{C}$ в течение 120 мин.

Праймеры к гену ТАТ (прямой - 5' -CCG CTA CTT CGA TCT TCA TCC-3', обратный - 5'-CCA TTG GAA CAA AAG GGT TCG-3') были сконструированы нами с помощью программы Oligo Primer Analysis Software v. 7 (https://www.oligo.net/downloads.html) на основе доступной последовательности mRNA гена тирозинаминотрансферазы Melissa officinalis (Gene Bank Accession No. JN863949). Амплификацию ДНК гена ТАТ проводили с использованием Taq DNA polymerase («Qiagen», Германия) с начальной денатурацией в течение 4 мин при $94{ }^{\circ} \mathrm{C}$, с последующими 30 циклами амплификации (1 мин при $94{ }^{\circ} \mathrm{C}, 1$ мин при $55{ }^{\circ} \mathrm{C}$ и 1 мин при $\left.72{ }^{\circ} \mathrm{C}\right)$ и заключительной элонгацией при $72{ }^{\circ} \mathrm{C}$ в течение 10 мин (термоциклер Eppendorf 5331 Mastercycler Gradient PCR, «Eppendorf», Германия).

Для изучения экспрессии гена ТАТ в присутствии разных концентраций $\mathrm{Cu}^{2+}$ использовали метод полуколичественной ПЦР и программное обеспечение Syngene GeneTools (Кембридж, Великобритания), которое позволяет количественно определять интенсивность флуоресценции полос амплифицированных фрагментов, разделенных в 1 \% агарозном геле, для оценки уровня экспрессии генов (29).

При определении содержания флавоноидов к 0,1 г свежей пробы добавляли 10 мл смеси этилового спирта с уксусной кислотой (1:99 v/v), растирали и центрифугировали 10 мин при 4000 об $\cdot$ мин $^{-1}$. Супернатант медленно нагревали на водяной бане (10 мин при $\left.80{ }^{\circ} \mathrm{C}\right)$. Поглощение измеряли при длинах волн 270, 300 и 330 нм с учетом коэффициента экстинкции $33000 \mathrm{M}^{-1} \cdot \mathrm{cm}^{-1}$. Содержание флавоноидов рассчитывали кумулятивно и выражали как мкмоль $\cdot \Gamma^{-1}$ сырой массы (30). 
Содержание антоцианов измеряли, как описано D.T. Krizek с соавт. (31). K 0,2 г свежего образца добавляли 3 мл метанола, подкисленного 0,1\% $\mathrm{HCl}$, измельчали и центрифугировали при 12000 об/мин в течение 20 мин при $4{ }^{\circ} \mathrm{C}$. Супернатант, содержащий пигмент, хранили в темноте в течение 24 ч. Поглощение измеряли при 550 нм, для расчета содержания антоцианова использовали коэффициент экстинкции $33000 \mathrm{M}^{-1} \cdot \mathrm{cm}^{-1}$, содержание антоцианов как мкмоль $\cdot \Gamma^{-1}$ сырой массы (31).

Белок экстрагировали из 0,5 г свежего образца, гомогенизированного в 50 мМ калий-фосфатном буфере (pH 7,5), содержащем 1 мМ EDTA и $1 \%$ поливинилпирролидон (PVP). Гомогенат центрифугировали при 11000 об мин $^{-1}$ в течение 20 мин при $4{ }^{\circ} \mathrm{C}$. В супернатанте измеряли содержание белка и исследовали активность ферментов (32). Общий белок в экстракте растений определяли по методу M.M. Bradford (33), используя бычий сывороточный альбумин (БСА) в качестве стандарта, оптическую плотность измеряли при $\lambda=595$ нм (33).

Для определения активности супероксиддисмутазы (SOD; EC 1.15.1.1) использовали метод C.N. Giannopolitis и S.K. Ries (34), который основан на подавлении ферментом фотохимического восстановления нитросинего тетразолия (NBT). Одна единица активности фермента определяется как его количество, необходимое для 50 \% ингибирования восстановления NBT до синего формазана в условиях освещения. Реакционная смесь включала метионин (13 мМ), NBT (75 мкM), рибофлавин (2 мкM), 50 мМ калийфосфатный буфер (pH 7,8) и 0,1 мМ EDTA. Оптическую плотность измеряли при $\lambda=650$ нм (34).

Активность каталазы (САТ: ЕС 1.11.1.6) измеряли согласно описанию R.S. Dhindsa с соавт. (35). Метод основан на способности фермента разлагать $\mathrm{H}_{2} \mathrm{O}_{2}$ (одна единица каталазы определяется как количество фермента, которое разлагает 1 мл $\mathrm{H}_{2} \mathrm{O}_{2}$ за 1 мин). Реакционная смесь включала $15 \mathrm{MM} \mathrm{H} \mathrm{O}_{2}$ и 50 мМ калий-фосфатный буфер (pH 7). Количество $\mathrm{H}_{2} \mathrm{O}_{2}$ в реакционной смеси через 1 мин и разницу в поглощении измеряли при $\lambda=240 \mathrm{нм}$, а затем определяли активность в $\mathrm{U} \cdot \mathrm{M \Gamma}^{-1}$ белка (35).

Активность пероксидазы (POD; EC 1.11.1.7) анализировали методом M.J. Plewa c соавт. (36) по поглощению $(\lambda=470$ нм) тетрагваякола, образованного в результате окисления гваякола, которое катализирует пероксидаза за 3 мин. Реакционная смесь содержала $4 \%$ гваякола, $1 \% \mathrm{H}_{2} \mathrm{O}_{2}$ и 50 мМ калий-фосфатный буфер (рH 7). Активность POD измеряли с использованием коэффициента экстинкции тетрагваякола, $\varepsilon=26,6 \mathrm{mM}^{-1} \cdot \mathrm{cm}^{-1}(36)$.

Все эксперименты проводили на случайных выборках в трех независимых повторностях. Рассчитывали средние $(M)$ и стандартные отклонения $( \pm \mathrm{SD})$. Для сравнения средних использовали множественный ранговый критерий Дункана. Также для анализа данных с помощью SAS 9.1.3 (SAS Institute, Кэри, Северная Каролина) применяли однофакторный дисперсионный анализ (ANOVA) при уровне значимости $\mathrm{p}=0,05$.

Результаты. Обработка проростков мелиссы разными концентрациями $\mathrm{Cu}^{2+}$ приводила к неодинаковому метаболическому ответу. Содержание RA в экспериментальных образцах измеряли с временем удерживания 16 мин в сравнении со стандартом (данные не приведены). Максимальное количество RA достигалось при обработке проростков $5 \mathrm{MM} \mathrm{Cu}^{2+}$ в течение 8 ч (примерно 36 мг/г сухой массы), что было в 3,5 раза больше, чем в контроле $\left(8,5\right.$ мг/г) (рис. 1, А). Обработка $10 \mathrm{MM} \mathrm{Cu}^{2+}$ привела к продукции RA в количестве 12 мг/г, что также значительно больше, чем в контроле. Содержание RA в образцах, обработанных более высокой концентрацией $\mathrm{Cu}^{2+}$, было таким же, как и в контроле. Накопление RA снижалось после 
16 ч обработки, и только для $10 \mathrm{MM} \mathrm{Cu}^{2+}$ результаты оказались сопоставимы с полученными при 8-часовом воздействии.

Экспрессию гена ТАТ изучали полуколичественным методом. Качество экстрагированной РНК определяли по полосам фрагментов амплификации ДНК генов $18 \mathrm{~S}$ рРНК и $28 \mathrm{~S}$ рРНК в 1 \% агарозном геле, которые четко наблюдались для всех образцов, что указывает на высокое качество экстрагированной РНК (рис. 2, А). После конструирования библиотеки кДНК и амплификации ДНК гена ТАТ уровень его экспрессии рассчитывали с помощью программного обеспечения GeneTools, для чего по 4 мкл каждого продукта ПЦР длиной 242 п.н. подвергали электрофорезу в 1 \% агарозном геле (см. рис. 2, Б).
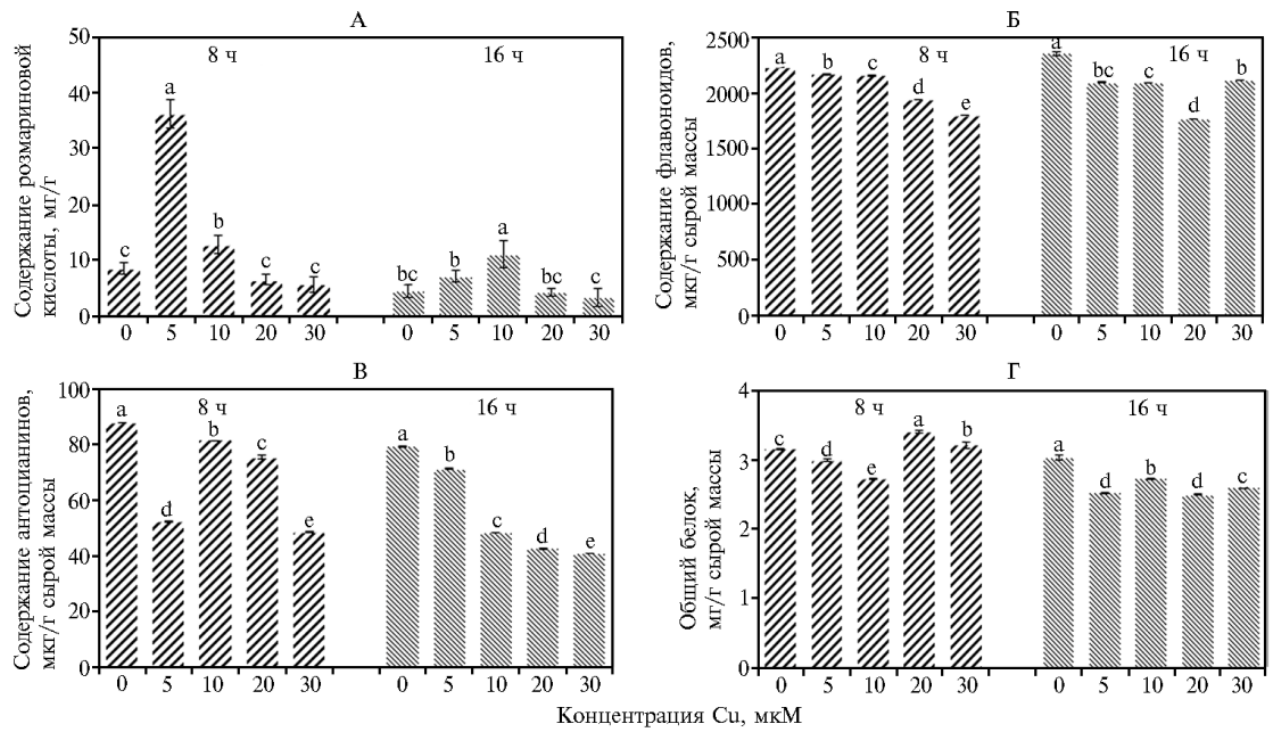

Рис. 1. Содержание розмариновой кислоты (А), флавоноидов (Б), антоцианов (В) и белка (Г) в проростках мелиссы под воздействием $\mathrm{Cu}^{2+}$ в разных концентрациях в зависимости от времени обработки $(n=3, M \pm \mathrm{SD}$, лабораторные тесты). Разными буквами отмечены статистически значимые различия при $\mathrm{p}<0,05$ в соответствии с множественным ранговым критерием Дункана.

Обработка проростков $\mathrm{Cu}^{2+}$ в концентрациях 5, 10 и 20 мкМ в течение 8 ч приводила к увеличению уровня экспрессии гена ТАТ по сравнению с контролем (см. рис. 2, В). Аналогичным образом проростки, обработанные 5 и $10 \mathrm{мкM} \mathrm{Cu}^{2+}$ в течение 16 ч, показали значительное повышение экспрессии гена ТАТ. Однако при увеличении концентрации $\mathrm{Cu}^{2+}$ в среде экспрессия этого гена снижалась, что в большей степени проявилось при длительном (16 ч) воздействии $\mathrm{Cu}^{2+}$, причем для концентрации $\mathrm{Cu}^{2+} 30$ мкМ при 16-часовой обработке соответствующих полос в геле мы не наблюдали.

Содержание флавоноидов в проростках, обработанных $\mathrm{Cu}^{2+}$, имело тенденцию к снижению с увеличением концентрации ионов в оба периода обработки (см. рис. 1, Б). Уменьшение содержания флавоноидов было сравнительно большим через 16 ч, чем через 8 ч, хотя обработка $\mathrm{Cu}^{2+}$ в концентрации 30 мкМ восстанавливала содержание флавоноидов примерно до значений, регистрируемых для 5 мкM $\mathrm{Cu}^{2+}$.

При обработке проростков мелиссы разными концентрациями $\mathrm{Cu}^{2+}$ отмечали тенденцию к снижению содержания антоцианов по сравнению с контролем независимо от длительности воздействия $\mathrm{Cu}^{2+}$ (см. рис. 1, В). Содержание антоцианов снижалось сильнее при 16-часовой обработке по 
сравнению с 8-часовой, а также при более высоких концентрациях $\mathrm{Cu}^{2+}$.
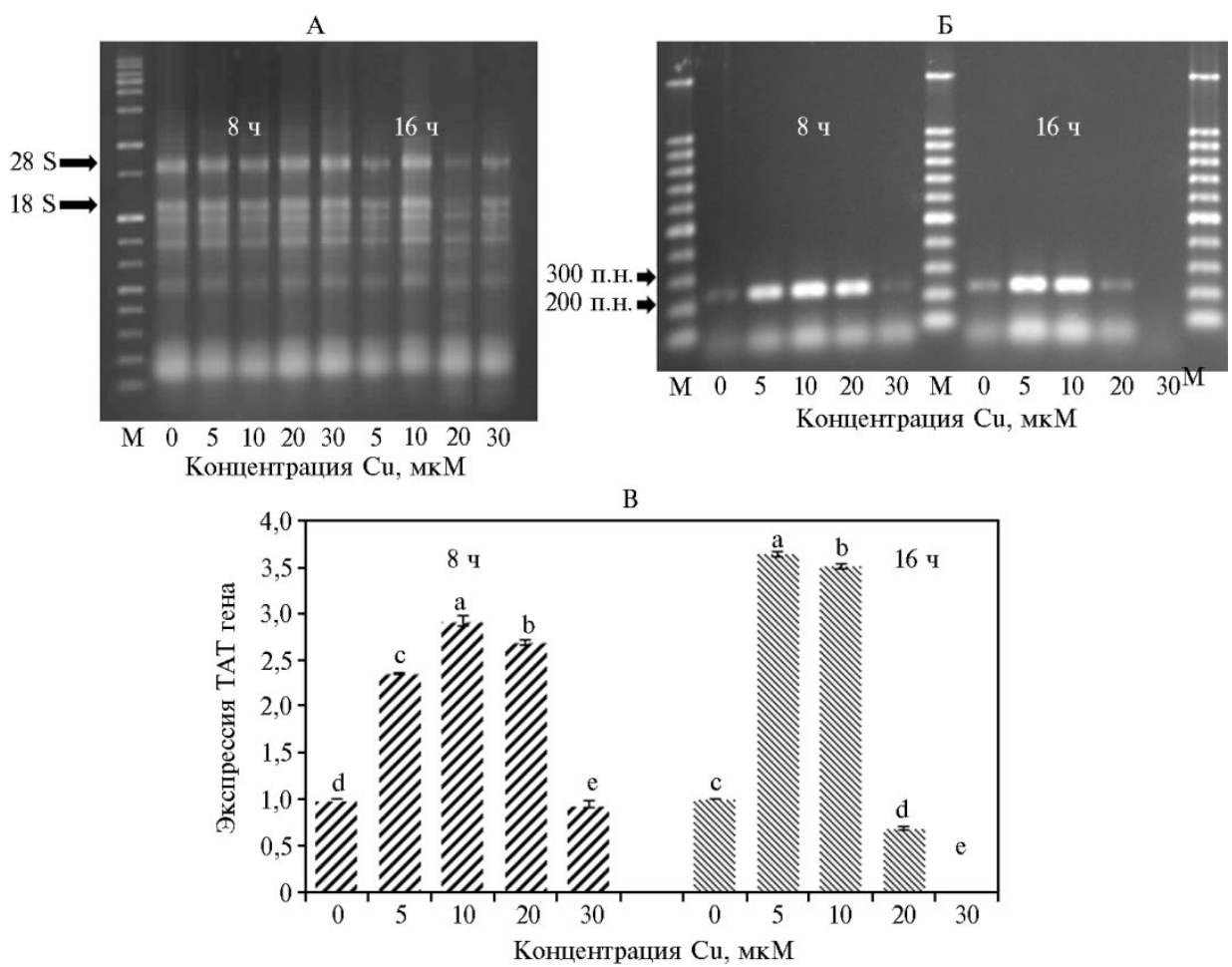

Рис. 2. Электрофоретическое разделение РНК из сеянцев мелиссы, обработанных Сu${ }^{2+}$ (А), фрагментов амплификации гена ТАТ в агарозном геле (Б) и сравнение экспрессии гена ТАТ (В) в проростках мелиссы под воздействием $\mathrm{Cu}^{2+}$ в разных концентрациях в зависимости от времени обработки ( $n=3, M \pm \mathrm{SD}$, лабораторные тесты). M - маркер молекулярных масc (GelPilot $1 \mathrm{~kb}$ Ladder, «Qiagen», Германия). Разными буквами отмечены статистически значимые различия при $\mathrm{p}<0,05$ в соответствии с множественным ранговым критерием Дункана.

Обработка проростков мелиссы разными концентрациями $\mathrm{Cu}^{2+}$ в оба периода приводила к значительному увеличению активности СОД и значительному снижению активности САТ по сравнению с контролем (табл.).

Активность супероксиддисмутазы (SOD), каталазы (CAT) и пероксидазы (POD) в проростках мелиссы под воздействием $\mathrm{Cu}^{2+}$ в разных концентрациях в зависимости от времени обработки $(n=3, M \pm \mathrm{SD}$, лабораторные тесты)

\begin{tabular}{|c|c|c|c|c|c|c|}
\hline \multirow{2}{*}{$\begin{array}{l}\text { Концентрация } \\
\mathrm{Cu}^{2+} \text {, мкM }\end{array}$} & \multicolumn{2}{|c|}{ SOD, U/мг белка } & \multicolumn{2}{|c|}{ СAT, U/мг белка } & \multicolumn{2}{|c|}{ POD, U/мг белка } \\
\hline & 8 ч & 16 ч & 8 ч & 16 ч & 8 ч & 16 ч \\
\hline 0 & $38,4 \pm 7,7 \mathrm{c}$ & $51,6 \pm 17,2^{\mathrm{e}}$ & $179,7 \pm 2,3^{\mathrm{a}}$ & $161,9 \pm 1,8^{a}$ & $3,61 \pm 0,4 \mathrm{~b}$ & $3,51 \pm 0,3^{\mathrm{d}}$ \\
\hline 5 & $395,6 \pm 15,6^{\mathrm{a}}$ & $142,8 \pm 10,8^{\mathrm{d}}$ & $89,3 \pm 1,1^{\mathrm{d}}$ & $156,7 \pm 0,9^{b}$ & $6,29 \pm 0,5^{a}$ & $7,65 \pm 0,4^{b}$ \\
\hline 10 & $277,0 \pm 19,7 \mathrm{~b}$ & $232,4 \pm 21,7 \mathrm{c}$ & $157,0 \pm 1,1^{b}$ & $105,7 \pm 1,3 \mathrm{c}$ & $5,87 \pm 0,1^{\mathrm{a}}$ & $6,15 \pm 0,2^{c}$ \\
\hline 20 & $376,8 \pm 16,3^{\mathrm{a}}$ & $382,9 \pm 25,5^{\mathrm{a}}$ & $86,6 \pm 1,1^{\mathrm{e}}$ & $93,7 \pm 1,8^{\mathrm{d}}$ & $5,58 \pm 0,4^{\mathrm{a}}$ & $8,86 \pm 0,4^{\mathrm{a}}$ \\
\hline 30 & $397,9 \pm 14,5^{\mathrm{a}}$ & $301,5 \pm 17,1^{b}$ & $107,3 \pm 0,7 \mathrm{c}$ & $65,9 \pm 1,4^{\mathrm{e}}$ & $5,81 \pm 0,1^{\mathrm{a}}$ & $6,99 \pm 0,4^{b}$ \\
\hline
\end{tabular}

П р и м е ч а и е. Разными буквами в каждой группе отмечены статистически значимые различия при $\mathrm{p}$ $\leq 0,05$ в соответствии с множественным ранговым критерием Дункана.

Активность POD была значительно повышена в проростках, обработанных $\mathrm{Cu}^{2+}$, причем повышение было пропорционально увеличению концентрации $\mathrm{Cu}^{2+}$ в среде. Исключение составил вариант с 16-часовой обработкой 30 мкM $\mathrm{Cu}^{2+}$, когда активность фермента осталась такой же, как для 5 мкM Cu${ }^{2+}$ (см. табл.).

Содержание растворимого белка в проростках, обработанных $\mathrm{Cu}^{2+}$, значительно снижалось при концентрациях 5 и 10 мкМ независимо от времени воздействия. Напротив, при концентрации $\mathrm{Cu}^{2+} 20$ и 30 мкМ и 8-ча- 
совой обработке содержание белка увеличивалось (см. рис. 1, Г). Однако более длительное воздействие все же значительно снизило содержание белка по сравнению с контролем.

В настоящем исследовании мы проанализировали влияние разных концентраций $\mathrm{Cu}^{2+}$ на накопление RA, экспрессию гена TAT, а также на антиоксидантную систему у 45-суточных проростков M. officinalis в зависимости от времени воздействия $\mathrm{Cu}^{2+}$. Согласно результатам, медь положительно влияла на содержание RA, особенно при более низких дозах (5 и 10 мкM), тогда как при более высоких концентрациях содержание RA было сходным с таковым в контроле. K максимальному накоплению RA приводило присутствие в среде 5 мкM $\mathrm{Cu}^{2+}$ при 8 ч обработки, когда содержание RA увеличилось в 3,5 раза по сравнению с контролем. Эти наблюдения согласуются с профилями экспрессии гена ТАТ. Следует отметить, что максимальная экспрессия гена наблюдалась в присутствии 5 и 10 мкМ $\mathrm{Cu}^{2+}$ после 16-часовой обработки, но она полностью подавлялась в варианте с 30 мкM Cu${ }^{2+}$. Интересно, что по сравнению с контролем содержание флавоноидов и антоцианов значительно снижалось, когда проростки обрабатывали разными концентрациями этого иона, особенно при воздействии в течение 16 ч. Поскольку флавоноиды, антоцианины и RA относятся к фенольным соединениями, можно предположить, что RA продуцируется в основном через тирозиновый путь (37). Кроме того, как недавно сообщили M.A. Nasiri-Bezenjani с соавт. (28), экспрессия генов RA и TAT в проростках мелиссы индуцировалась дрожжевым экстрактом через 17 ч, и результаты выявили схожий характер изменений этих двух параметров. Снижение содержания флавоноидов и антоцианов также согласуется с нашим недавним сообщением, в котором мы показали уменьшение накопления этих метаболитов, когда проростки мелиссы обрабатывали разными концентрациями $\mathrm{Fe}^{2+}$ (27). Обработка проростков Pinus sylvestris L. высокими концентрациями меди или никеля показала снижение аккумуляции фенольных соединений (38). Основываясь на полученных данных, допустимо предположить, что снижение содержания фенольных соединений может быть связано с подавлением экспрессии других генов (например, гена PAL), участвующих в биосинтезе этих метаболитов, или с деградацией ферментов, вовлеченных в этот биосинтетический путь, из-за высокой токсичности указанных ионов в среде. PAL - один из наиболее важных ферментов в биосинтезе фенилпропаноидов (1) - может активироваться при синтезе вторичных метаболитов, таких как простые фенолы, антоцианы, флавоноиды и лигнины, для защиты растений в стрессовых условиях (39). Предшествующие исследования показали, что активность PAL была увеличена в листьях Phyllanthus tenellus и Camellia sinensis, обработанных медью, ртутью и никелем $(14,15)$.

По сравнению с другими абиотическими стрессорами тяжелые металлы индуцируют синтез белков теплового шока (HSP) и образование сигнальных молекул, таких как салициловая кислота, абсцизовая кислота, жасмонаты и этилен (40). Было высказано предположение, что свободные радикалы играют двойственную роль в клетках, поскольку при более высоких концентрациях они могут повреждать клеточную мембрану, нуклеиновые кислоты и белки (41), а при пониженных - действовать как сигнальные молекулы (40). Жасмонат как ключевая сигнальная молекула играет важную роль в настройке сигнальной сети, что приводит к биосинтезу вторичных метаболитов растений (42). Было выяснено влияние этих соединений на биосинтез различных типов вторичных метаболитов, таких как алкалоиды, терпеноиды, гликозинолаты и фенилпропаноиды (43). Доказано быстрое 
накопление жасмоновой кислоты у Phaseolus coccineus и Arabidopsis thaliana после обработки медью (44). Сообщалось об увеличении продукции RA при воздействии некоторых элиситоров (дрожжевой экстракт и метилжасмонат) у нескольких видов растений, включая Orthosiphon aristatus (45), Coleus blumei (46) и M. officinalis (28). Q. Yan с соавт. (13) заявили, что увеличение содержания RA в растениях Salvia miltiorrhiza после обработки дрожжевым экстрактом и ионами серебра связано с увеличением активности гена TAT. Учитывая антиоксидантные свойства RA (47), допустимо предположить, что увеличение содержания RA в проростках, обработанных $\mathrm{Cu}^{2+}$, может быть связано с индукцией АФК и активацией сигнального пути, например, эндогенного жасмоната (48) и, как следствие, активацией генов, участвующих в системе защиты (например, ТАТ). Снижение уровня этих соединений изза антиоксидантных эффектов связано с активацией других антиоксидантных систем, например с участием ферментов или деградацией либо инактивацией ферментов, которые вовлечены в биосинтез таких соединений (49). Интересно, что по сравнению с контролем в проростках, обработанных $\mathrm{Cu}^{2+}$, активность SOD, которая является первым ферментом детоксикации АФК (50) и играет важную роль в превращении супероксидных радикалов в $\mathrm{H}_{2} \mathrm{O}_{2}$ и $\mathrm{O}_{2}$ (51), увеличивалась после 8-часового воздействия. В нашем исследовании в проростках, обработанных $\mathrm{Cu}^{2+}$, концентрация POD, которая участвует в обезвреживании перекиси водорода внутри клетки (52), была значительно увеличена. Однако при этом активность САТ - другого фермента, участвующего в обезвреживании пероксида водорода в пероксисомах (53), у проростков, обработанных $\mathrm{Cu}^{2+}$, была значительно снижена. Таким образом, похоже, что проростки мелиссы удаляют свободные радикалы, используя экспрессию антиоксидантных ферментов, таких как SOD и POD.

Многие исследования показали, что SOD, CAT и POD необходимы для защиты клеток от побочных эффектов АФК (50). Е. Miteva с соавт. (54) заявили, что добавление мышьяковой кислоты в культуральную среду привело к значительному увеличению активности POD в томатах (Lycopersicon esculentum Mill.), что указывает на участие POD в противодействии вредным последствиям окислительного стресса (54). Более того, сообщалось о значительном увеличении активности некоторых ферментов, например пероксидазы и супероксиддисмутазы, у краснокочанной капусты (Brassica oleracea L.). Это растение использовало антиоксиданты ферментативной и неферментативной природы при стрессе, вызванном тяжелыми металлами (55). S.H. Wang с соавт. (56) продемонстрировали, что обработка проростков Brassica juncea L. медью приводила к увеличению активности SOD, POD и снижению активности САТ, что согласуется с результатами представляемого нами исследования. Снижение активности САТ может быть связано с более низким сродством к $\mathrm{H}_{2} \mathrm{O}_{2}$ или ингибированием из-за присутствия высоких концентраций тяжелых металлов, таких как медь $(57,58)$. Уместно отметить, что кадмий вызывал окисление CAT у гороха (Pisum sativum L.) и, как следствие, приводил к снижению ее активности (44). Кроме того, в токсичных условиях, вызванных тяжелыми металлами, отсутствие системы нейтрализации побочных продуктов реакционной активности кислородных радикалов привело к образованию гидроксильных радикалов в результате реакций Фентона и Габера-Вейса (59). Эти радикалы могут изменять ферментативную активность, экспрессию генов, содержание белка и содержание растворимого сахара, высвобождать кальций в клетке, а также вызывать необратимые повреждения плазматической мембраны и нуклеиновой 
кислоты, как сообщалось ранее (60). Следовательно, снижение содержания белка в проростках, обработанных $\mathrm{Cu}^{2+}$, можно объяснить накоплением этих радикалов. Снижение содержания белка в проростках пшеницы в присутствии $\mathrm{Cu}^{2+}$ было показано D. Singh с соавт. (61). Кроме того, N. Singh с coавт. (62) сообщили, что содержание белка у Pteris vittata было снижено изза окислительного стресса, вызванного мышьяковой кислотой и деградацией некоторых белков. В то же время повышенное количество растворимых белков при 8-часовой обработке 20 и $30 \mathrm{мкM} \mathrm{Cu}^{2+}$ может быть связано с синтезом белков теплового шока. Таким образом, выявленное нами снижение общего содержания флавоноидов, антоцианов и RA в проростках, обработанных $\mathrm{Cu}^{2+}$, может быть связано с ингибированием ферментов, участвующих в биосинтезе RA, или с деградацией этих ферментов из-за окислительного стресса.

Обобщая, можно сделать вывод, что ион $\mathrm{Cu}^{2+}$ в использованных в этом исследовании концентрациях приводит к окислительному стрессу изза индукции свободных радикалов. Образование таких радикалов и особенно перекиси водорода непосредственно активирует сигнальные пути или индуцирует экспрессию других генов, участвующих в этих путях, посредством биосинтеза определенных соединений, таких как гормоны растений (48). Повышение уровня экспрессии гена ТАТ может быть связано с сигнальной ролью этих радикалов, что, в свою очередь, приводит к синтезу $\mathrm{RA}$, когда проростки обрабатывают низкими концентрациями $\mathrm{Cu}^{2+}$. Хотя образование свободных радикалов обычно совпадает с увеличением активности SOD и POD, повышенные концентрации свободных радикалов приводят к деградации некоторых белков, ограничению их функций или снижению экспрессии генов этих белков. Такое предположение согласуется с наблюдаемым нами уменьшением общего содержания белка, а также активности антиоксидантных ферментов и значительным снижением экспрессии гена ТАТ при обработке проростков максимальной концентрацией ионов меди. Наблюдаемый эффект также может быть связан со снижением содержания флавоноидов и антоцианов наряду со снижением продукции RA в проростках, обработанных $\mathrm{Cu}^{2+}$, при более высоких концентрациях ионов. В дальнейших экспериментах мы планируем изучить влияние меди на продукцию RA в условиях почвенных систем. Если положительное влияние $\mathrm{Cu}^{2+}$ на накопление RA в растениях мелиссы подтвердится, то применение обработок $\mathrm{Cu}^{2+}$ повысит ценность этой культуры для растениеводства и в целом послужит интересам биоэкономики.

Итак, в невысоких концентрациях ионы $\mathrm{Cu}^{2+}$ положительно влияют на накопление розмариновой кислоты (RA) в проростках мелиссы независимо от длительности обработки, при этом также отмечалось усиление экспрессии гена тирозинаминотрансферазы (ТАТ) - фермента, участвующего в образовании RA по метаболическому пути, идущему от тирозина. При воздействии максимальной концентрации $\mathrm{Cu}^{2+}$ в течение 16 ч содержание RA и экспрессия гена TAT значительно снижается. Одновременно отмечается повышение активности супероксиддисмутазы и пероксидазы. Последнее может указывать на то, что меньшие концентрации $\mathrm{Cu}^{2+}$ вызывают окислительный стресс. Активные формы кислорода (АФК), которые действуют как сигнальные молекулы, накапливаются и служат индукторами экспрессии гена TAT, в результате чего усиливается образование RA. Однако при самой высокой концентрации ионов меди АФК подавляют экспрессию гена ТАТ. 


\section{ЛИТЕРАТ УРА}

1. Petersen M., Simmonds M.S. Rosmarinic acid. Phytochemistry, 2003, 62(2): 121-125 (doi: 10.1016/s0031-9422(02)00513-7).

2. Dastmalchi K., Dorman H.T.D., Oinonen P.P., Darwis Y., Laakso I., Hiltunen R. Chemical composition and in vitro antioxidative activity of a lemon balm (Melissa officinalis L.) extract. LWT-Food Science and Technology, 2008, 41(3): 391-400 (doi: 10.1016/j.lwt.2007.03.007).

3. Rocha J., Eduardo-Figueira M., Barateiro A., Fernandes A., Brites D., Bronze R., Duarte C.M., Serra A.T., Pinto R., Freitas M., Fernandes E., Silva-Lima B., Mota-Filipe H., Sepodes B. Antiinflammatory effect of rosmarinic acid and an extract of Rosmarinus officinalis in rat models of local and systemic inflammation. Basic \& Clinical Pharmacology \& Toxicology, 2015, 116(5): 398413 (doi: 10.1111/bcpt.12335).

4. Swarup V., Ghosh J., Ghosh S., Saxena A., Basu A. Antiviral and anti-inflammatory effects of rosmarinic acid in an experimental murine model of Japanese encephalitis. Antimicrobial Agents and Chemotherapy, 2007, 51(9): 3367-3370 (doi: 10.1128/AAC.00041-07).

5. Nascimento G.G.F., Locatelli J., Freitas P.C., Silva G.L. Antibacterial activity of plant extracts and phytochemicals on antibiotic-resistant bacteria. Brazilian Journal of Microbiology, 2000, 31(4): 247-256 (doi: 10.1590/S1517-83822000000400003).

6. Capecka E., Mareczek A., Leja M. Antioxidant activity of fresh and dry herbs of some Lamiaceae species. Food Chemistry, 2005, 93(2): 223-226 (doi: 10.1016/j.foodchem.2004.09.020).

7. Link A., Balaguer F., Goel A. Cancer chemoprevention by dietary polyphenols: promising role for epigenetics. Biochemical Pharmacology, 2010, 80(12): 1771-1792 (doi: 10.1016/j.bcp.2010.06.036).

8. Sanbongi C., Takano H., Osakabe N., Sasa N., Natsume M., Yanagisawa R., Inoue K.I., Sadakane K., Ichinose T., Yoshikawa T. Rosmarinic acid in perilla extract inhibits allergic inflammation induced by mite allergen, in a mouse model. Clinical \& Experimental Allergy, 2004, 34(6): 971-977 (doi: d10.1111/j.1365-2222.2004.01979.x).

9. Caleja C., Barros L., Barreira J.C.M., Ciric A., Sokovic M., Calhelha R.C., Beatriz M., Oliveira P.P., Ferreira I.C.F.R. Suitability of lemon balm (Melissa officinalis L.) extract rich in rosmarinic acid as a potential enhancer of functional properties in cupcakes. Food Chemistry, 2018, 250: 67-74 (doi: 10.1016/j.foodchem.2018.01.034).

10. Gertlowski C., Petersen M. Influence of the carbon source on growth and rosmarinic acid production in suspension-cultures of Coleus blumei. Plant Cell Tissue and Organ Culture, 1993, 34(2): 183-190 (doi: 10.1007/BF00036100).

11. Krzyzanowska J., Czubacka A., Pecio L., Przybys M., Doroszewska T., Stochmal A., Oleszek W. The effects of jasmonic acid and methyl jasmonate on rosmarinic acid production in Mentha piperita cell suspension cultures. Plant Cell, Tissue and Organ Culture (PCTOC), 2012, 108(1): 73-81 (doi: 10.1007/s11240-011-0014-8).

12. Sahu R., Gangopadhyay M., Dewanjee S. Elicitor-induced rosmarinic acid accumulation and secondary metabolism enzyme activities in Solenostemon scutellarioides. Acta Physiologiae Plantarum, 2013, 35(5): 1473-1481 (doi: 10.1007/s11738-012-1188-3).

13. Yan Q., Shi M., Ng J., Wu J.Y. Elicitor-induced rosmarinic acid accumulation and secondary metabolism enzyme activities in Salvia miltiorrhiza hairy roots. Plant Science, 2006, 170(4): 853858 (doi: 10.1016/j.plantsci.2005.12.004).

14. Santiago L.J.M., Louro R.P., De Oliveira D.E. Compartmentation of phenolic compounds and phenylalanine ammonia-lyase in leaves of Phyllanthus tenellus Roxb. and their induction by copper sulphate. Annals of Botany, 2000, 86(5): 1023-1032 (doi: 10.1006/anbo.2000.1271).

15. Basak M., Sharma M., Chakraborty U. Biochemical responses of Camellia sinensis (L.) O. Kuntze to heavy metal stress. Journal of Environmental Biology, 2001, 22(1): 37-41.

16. Yruela I. Copper in plants. Brazilian Journal of Plant Physiology, 2005, 17(1): 145-156 (doi: 10.1590/S1677-04202005000100012).

17. Marschner H. Marschner's mineral nutrition of higher plants /P. Marschner (ed.). Academic Press, 2011.

18. Gaetke L.M., Chow C.K. Copper toxicity, oxidative stress, and antioxidant nutrients. Toxicology, 2003, 189(1-2): 147-163 (doi: 10.1016/s0300-483x(03)00159-8).

19. Sims J.T., Johnson G.V. Micronutrient soil tests. In: Micronutrients in agriculture /J.J. Mortvedt (ed.). SSSA Book Series, 1991 (dol: 10.2136/sssabookser4.2ed.c12).

20. Groppa M.D., Tomaro M.L., Benavides M.P. Polyamines and heavy metal stress: the antioxidant behavior of spermine in cadmium- and copper-treated wheat leaves. Biometals, 2007, 20(2): 185 195 (doi: 10.1007/s10534-006-9026-y).

21. Ignat I., Volf I., Popa V.I. A critical review of methods for characterisation of polyphenolic compounds in fruits and vegetables. Food Chemistry, 2011, 126(4): 1821-1835 (doi: 10.1016/j.foodchem.2010.12.026). 
22. Trouillas P., Sancho-Garcia J.C., De Freitas V., Gierschner J., Otyepka M., Dangles O. Stabilizing and modulating color by copigmentation: insights from theory and experiment. Chemical Reviews, 2016, 116(9): 4937-4982 (doi: 10.1021/acs.chemrev.5b00507).

23. Lattanzio V., Lattanzio V.M., Cardinali A. Role of phenolics in the resistance mechanisms of plants against fungal pathogens and insects. In: Phytochemistry: Advances in Research. Research Signpost, Trivandrum, India, 2006: 23-67.

24. Laura A., Moreno-Escamilla J.O., Rodrigo-Garcha J., Alvarez-Parrilla E. Phenolic compounds. In: Postharvest physiology and biochemistry of fruits and vegetables /E. Yahia, A. Carrillo-Lopez (eds.). Woodhead Publishing, 2019: 253-271.

25. Cushnie T.P., Hamilton V.E., Lamb A.J. Assessment of the antibacterial activity of selected flavonoids and consideration of discrepancies between previous reports. Microbiological Research, 2003, 158(4): 281-289 (doi: 10.1078/0944-5013-00206).

26. Aksoy L., Kolay E., Agilonu Y., Aslan Z., Kargioglu M. Free radical scavenging activity, total phenolic content, total antioxidant status, and total oxidant status of endemic Thermopsis turcica. Saudi Journal of Biological Sciences, 2013, 20(3): 235-239 (doi: 10.1016/j.sjbs.2013.02.003).

27. Esmaeilzadeh-Salestani K., Riahi-Madvar A. Effects of iron ions on rosmarinic acid production and antioxidant system in Melissa officinalis L. seedlings. Annual Research \& Review in Biology, 2014, 4(22): 3359-3372 (doi: 10.9734/ARRB/2014/9300).

28. Nasiri-Bezenjani M.A., Riahi-Madvar A., Baghizadeh A., Ahmadi A.R. Rosmarinic acid production and expression of tyrosine aminotransferase gene in Melissa officinalis seedlings in response to yeast extract. Journal of Agricultural Science and Technology, 2014, 16(4): 921-930.

29. Al-Bader M.D. Estrogen receptors alpha and beta in rat placenta: detection by RT-PCR, real time PCR and Western blotting. Reproductive Biology and Endocrinology, 2006, 4: 13 (doi: 10.1186/1477-7827-4-13).

30. Krizek D.T., Britz S.J., Mirecki R.M. Inhibitory effects of ambient levels of solar UV-A and UVB radiation on growth of cv. New Red Fire lettuce. Physiologia Plantarum, 1998, 103(1): 1-7 (doi: 10.1034/j.1399-3054.1998.1030101.x).

31. Krizek D.T., Kramer G.F., Upadhyaya A., Mirecki R.M. UV-B response of cucumber seedlings grown under metal halide and high pressure sodium/deluxe lamps. Physiologia Plantarum, 1993, 88(2): 350-358 (doi: 10.1111/j.1399-3054.1993.tb05509.x).

32. Sharma P., Dubey R.S. Drought induces oxidative stress and enhances the activities of antioxidant enzymes in growing rice seedlings. Plant Growth Regulation, 2005, 46(3): 209-221 (doi: 10.1007/s10725-005-0002-2).

33. Bradford M.M. A rapid and sensitive method for the quantitation of microgram quantities of protein utilizing the principle of protein-dye binding. Analytical Biochemistry, 1976, 72(1): 248254 (doi: 10.1006/abio.1976.9999).

34. Giannopolitis C.N., Ries S.K. Superoxide dismutases: I. Occurrence in higher plants. Plant Physiology, 1977, 59(2): 309-314 (doi: 10.1104/pp.59.2.309).

35. Dhindsa R.S., Plumbdhindsa P., Thorpe T.A. Leaf senescence: correlated with increased levels of membrane-permeability and lipid-peroxidation, and decreased levels of superoxide-dismutase and catalase. Journal of Experimental Botany, 1981, 32(1): 93-101 (doi: 10.1093/jxb/32.1.93).

36. Plewa M.J., Smith S.R., Wagner E.D. Diethyldithiocarbamate suppresses the plant activation of aromatic-amines into mutagens by inhibiting tobacco cell peroxidase. Mutation Research/Fundamental and Molecular Mechanisms of Mutagenesis, 1991, 247(1): $57-64$ (dol: 10.1016/00275107(91)90033-K).

37. Ru M., Wang K., Bai Z., Peng L., He S., Wang Y., Liang Z. A tyrosine aminotransferase involved in rosmarinic acid biosynthesis in Prunella vulgaris L. Scientific Reports, 2017, 7: 4892 (doi: 10.1038/s41598-017-05290-4).

38. Roitto M., Rautio P., Julkunen-Tiitto R., Kukkola E., Huttunen S. Changes in the concentrations of phenolics and photosynthates in Scots pine (Pinus sylvestris L.) seedlings exposed to nickel and copper. Environmental Pollution, 2005, 137(3): 603-609 (doi: 10.1016/j.envpol.2005.01.046).

39. Dixon R.A., Paiva N.L. Stress-induced phenylpropanoid metabolism. The Plant Cell, 1995, 7(7): 1085-1097 (doi: 10.1105/tpc.7.7.1085).

40. Romero-Puertas M.C., Corpas F.J., Rodriguez-Serrano M., Gomez M., Del Rio L.A., Sandalio L.M. Differential expression and regulation of antioxidative enzymes by cadmium in pea plants. Journal of Plant Physiology, 2007, 164(10): 1346-1357 (doi: 10.1016/j.jplph.2006.06.018).

41. Lombardi L., Sebastiani L. Copper toxicity in Prunus cerasifera: growth and antioxidant enzymes responses of in vitro grown plants. Plant Science, 2005, 168(3): 797-802 (doi: 10.1016/j.plantsci.2004.10.012).

42. Zhou M.L., Zhu X.M., Shao J.R., Wu Y.M., Tang Y.X. Transcriptional response of the catharanthine biosynthesis pathway to methyl jasmonate/nitric oxide elicitation in Catharanthus roseus hairy root culture. Applied Microbiology and Biotechnology, 2010, 88(3): 737-750 (doi: 10.1007/s00253-010-2822-x).

43. Memelink J., Verpoorte R., Kijne J.W. ORCAnization of jasmonate-responsive gene expression in alkaloid metabolism. Trends in Plant Science, 2001, 6(5): 212-219 (doi: 10.1016/s1360- 
1385(01)01924-0).

44. Maksymiec W., Wianowska D., Dawidowicz A.L., Radkiewicz S., Mardarowicz M., Krupa Z. The level of jasmonic acid in Arabidopsis thaliana and Phaseolus coccineus plants under heavy metal stress. Journal of Plant Physiology, 2005, 162(12): 1338-1346 (doi: 10.1016/j.jplph.2005.01.013).

45. Mizukami H., Ogawa T., Ohashi H., Ellis B.E. Induction of rosmarinic acid biosynthesis in Lithospermum erythrorhizon cell suspension cultures by yeast extract. Plant Cell Reports, 1992, 11(9): 480-483 (doi: 10.1007/BF00232695).

46. Szabo E., Thelen A., Petersen M. Fungal elicitor preparations and methyl jasmonate enhance rosmarinic acid accumulation in suspension cultures of Coleus blumei. Plant Cell Reports, 1999, 18(6): 485-489 (doi: 10.1007/s002990050608).

47. Park S.U., Uddin M.R., Xu H., Kim Y.K., Lee S.Y. Biotechnological applications for rosmarinic acid production in plant. African Journal of Biotechnology, 2008, 7(25): 4959-4965.

48. Karuppanapandian T., Moon J.C., Kim C., Manoharan K., Kim W. Reactive oxygen species in plants: their generation, signal transduction, and scavenging mechanisms. Australian Journal of Crop Science, 2011, 5(6): 709-725.

49. Achamlale S., Rezzonico B., Grignon-Dubois M. Rosmarinic acid from beach waste: isolation and HPLC quantification in Zostera detritus from Arcachon lagoon. Food Chemistry, 2009, 113(4): 878-883 (doi: 10.1016/j.foodchem.2008.07.040).

50. Garnczarska M., Ratajczak L. Metabolic responses of Lemna minor to lead ions II. Induction of antioxidant enzymes in roots. Acta Physiologiae Plantarum, 2000, 22(4): 429-432 (doi: 10.1007/s11738-000-0084-4).

51. Fukai T., Ushio-Fukai M. Superoxide dismutases: role in redox signaling, vascular function, and diseases. Antioxidants \& Redox Signaling, 2011, 15(6): 1583-1606 (doi: 10.1089/ars.2011.3999).

52. Jimenez A., Hernandez J.A., Del Rio L.A., Sevilla F. Evidence for the presence of the ascorbateglutathione cycle in mitochondria and peroxisomes of pea leaves. Plant Physiology, 1997, 114(1): 275-284 (doi: 10.1104/pp.114.1.275).

53. Khatun S., Ali M.B., Hahn E.-J., Paek K.-Y. Copper toxicity in Withania somnifera: growth and antioxidant enzymes responses of in vitro grown plants. Environmental and Experimental Botany, 2008, 64(3): 279-285 (doi: 10.1016/j.envexpbot.2008.02.004).

54. Miteva E., Hristova D., Nenova V., Maneva S. Arsenic as a factor affecting virus infection in tomato plants: changes in plant growth, peroxidase activity and chloroplast pigments. Scientia Horticulturae, 2005, 105(3): 343-358 (doi: 10.1016/j.scienta.2005.01.026).

55. Posmyk M.M., Kontek R., Janas K.M. Antioxidant enzymes activity and phenolic compounds content in red cabbage seedlings exposed to copper stress. Ecotoxicology and Environmental Safety, 2009, 72(2): 596-602 (doi: 10.1016/j.ecoenv.2008.04.024).

56. Wang S.H., Yang Z.M., Yang H., Lu B., Li S.Q., Lu Y.P. Copper-induced stress and antioxidative responses in roots of Brassica juncea L. Botanical Bulletin of Academia Sinica, 2004, 45(3): 203-212.

57. Choudhary M., Jetley U.K., Abash Khan M., Zutshi S., Fatma T. Effect of heavy metal stress on proline, malondialdehyde, and superoxide dismutase activity in the cyanobacterium Spirulina platensis-S5. Ecotoxicology and Environmental Safety, 2007, 66(2): 204-209 (doi: 10.1016/j.ecoenv.2006.02.002).

58. Zhang B., Li X., Chen D., Wang J. Effects of 1-octyl-3-methylimidazolium bromide on the antioxidant system of Lemna minor. Protoplasma, 2013, 250(1): 103-110 (doi: 10.1007/s00709012-0379-5).

59. Mittler R., Vanderauwera S., Gollery M., Van Breusegem F. Reactive oxygen gene network of plants. Trends In Plant Science, 2004, 9(10): 490-498 (doi: 10.1016/j.tplants.2004.08.009).

60. Mishra S., Srivastava S., Tripathi R.D., Govindarajan R., Kuriakose S.V., Prasad M.N. Phytochelatin synthesis and response of antioxidants during cadmium stress in Bacopa monnieri L. Plant Physiology and Biochemistry, 2006, 44(1): 25-37 (doi: 10.1016/j.plaphy.2006.01.007).

61. Singh D., Nath K., Sharma Y.K. Response of wheat seed germination and seedling growth under copper stress. Journal of Environmental Biology, 2007, 28(2 Suppl): 409-414.

62. Singh N., Ma L.Q., Srivastava M., Rathinasabapathi B. Metabolic adaptations to arsenic-induced oxidative stress in Pteris vittata L and Pteris ensiformis L. Plant Science, 2006, 170(2): 274-282 (doi: 10.1016/j.plantsci.2005.08.013).

${ }^{1}$ Department of Biotechnology,

Faculty of Science and Modern Technology,

Поступила в редакцию

Graduate University of Advanced Technology,

18 августа 2020 года

P.O. Box 117-76315, Kerman, Iran,

e-mail: k1.esmaeilzadeh@gmail.com $₫$;

${ }^{2}$ Department of Biotechnology, Institute of Science

and High Technology and Environmental Sciences,

Graduate University of Advanced Technology,

P.O. Box 117-76315, Kerman, Iran,

e-mail: riahi.ali@gmail.com; 
${ }^{3}$ Department of Molecular and Cell Biology,

Faculty of Basic Sciences,

Kosar University of Bojnord,

P.O. Box 94156-15458, Bojnord, Iran;

${ }^{4}$ Department of Horticulture, Agriculture Faculty,

University of Guilan,

P.O. Box 1841, Rasht, Iran,

e-mail: maziar.elm@gmail.com;

${ }^{5}$ Chair of Crop Science and Plant Biology,

Institute of Agricultural and Environmental Sciences,

Estonian University of Life Sciences,

Fr. R. Kreutzwaldi 1, EE51014 Tartu, Estonia,

e-mail: khaleghdoust@gmail.com, evelin.loit@emu.ee

Sel'skokhozyaistvennaya biologiya [Agricultural Biology], 2021, V. 56, № 3, pp. 578-590

\title{
COPPER ION INDUCED PRODUCTION OF ROSMARINIC ACID IN LEMON BALM (Melissa officinalis L.) SEEDLINGS
}

\author{
K. Esmaeilzadeh-Salestani $1,5 \bowtie$, A. Riahi-Madvar2, 3, M.A. Maziyar ${ }^{4}$, \\ B. Khaleghdoust ${ }^{5}$, E. Loit $^{5}$
}

\begin{abstract}
${ }^{1}$ Department of Biotechnology, Faculty of Science and Modern Technology, Graduate University of Advanced Technology, P.O. Box 117-76315, Kerman, Iran, e-mail k1.esmaeilzadeh@gmail.com ( $\square$ corresponding author);

${ }^{2}$ Department of Biotechnology, Institute of Science and High Technology and Environmental Sciences, Graduate University of Advanced Technology, P.O. Box 117-76315, Kerman, Iran, e-mail riahi.ali@gmail.com;

${ }^{3}$ Department of Molecular and Cell Biology, Faculty of Basic Sciences, Kosar University of Bojnord, P.O. Box 9415615458, Bojnord, Iran;

${ }^{4}$ Department of Horticulture, Agriculture faculty, University of Guilan, P.O. Box 1841, Rasht, Iran, e-mail maziar.elm@gmail.com;

${ }^{5}$ Chair of Crop Science and Plant Biology, Institute of Agricultural and Environmental Sciences, Estonian University of Life Sciences, Fr. R. Kreutzwaldi 1, EE51014 Tartu, Estonia, e-mail khaleghdoust@gmail.com, evelin.loit@emu.ee ORCID

Esmaeilzadeh-Salestani K. orcid.org/0000-0002-6882-7616 Khaleghdoust B. orcid.org/0000-0001-5070-8080

Riahi-Madvar A. orcid.org/0000-0002-9577-3895 Loit E. orcid.org/0000-0001-6635-8740

Maziyar M.A. orcid.org/0000-0001-6480-8410

The authors declare no conflict of interests

Acknowledgements:

We are thankful to Pavel Covali for critically reading the Russian version of this manuscript

The authors gratefully acknowledge the financial support provided by Institute of Science and High Technology and Environmental Sciences, Graduate University of Advanced Technology, Kerman, Iran.

Received August 18, 2020 doi: 10.15389/agrobiology.2021.3.578eng
\end{abstract}

\section{Abstract}

Rosmarinic acid (RA), one of the most important active ingredients of lemon balm (Melissa officinalis L.), exhibits antiviral, antibacterial, antioxidative and anticancer properties. Furthermore, it can improve functionality in baking process. $\mathrm{Cu}$ acts as a cofactor of several proteins and plays a key role in photosynthesis, respiration, lignin synthesis, response to oxidative stress and cell wall metabolism, but can be toxic to plants in high concentrations. We hypothesized that abiotic stresses, as one of the external factors inducing the defense mechanism of plants, may contribute to the production of secondary metabolites, especially RA, in representatives of the Lamiaceae family. In current study, RA accumulation, expression of tyrosine aminotransferase gene (TAT), contents of flavonoid and anthocyanin as well as antioxidant enzymes activities were investigated in 45-day-old $M$. officinalis seedlings after treatment with different concentrations of $\mathrm{Cu}^{2+}(0,5,10,20$, and $30 \mu \mathrm{M})$. Samples were collected and analyzed after 8 and 16 hours of treatment. Lower concentrations of $\mathrm{Cu}^{2+}$ positively affected RA accumulation at both aforementioned treatment times, which is consistent with the increase in TAT gene expression profile. Flavonoid, anthocyanin and soluble protein contents of the seedlings significantly decreased (except at 20 and $30 \mu \mathrm{M} \mathrm{Cu}^{2+}$-treated seedlings after 8 hours). RA content and expression of TAT gene decreased significantly at the highest concentration of $\mathrm{Cu}^{2+}$ for 16 hours. Concurrently, elevated levels of superoxide dismutase and peroxidase activities were measured in these seedlings. Latter can indicate that lower concentrations of $\mathrm{Cu}^{2+}$ cause oxidative stress. Reactive oxygen species (ROS), which act as signal molecules, are accumulated and due to their positive effects on the expression of TAT gene more RA is produced. In contrast, at the highest concentration of copper ions, ROS suppressed TAT gene expression and prevented the degradation of the gene product.

Keywords: antioxidant enzyme, superoxide dismutase, catalase, peroxidase, Melissa officinalis, rosmarinic acid, flavonoids, anthocyanins, tyrosine aminotransferase. 